\title{
Research Concerning the Optimization of the Mechanism of the Conventional Sucker Rod Pumping Units
}

\author{
GEORGETA TOMA* \\ Petroleum-Gas University of Ploiesti, 39 Bucuresti Blvd., 100680, Ploiesti, Romania
}

\begin{abstract}
Finding optimal solutions to design the mechanism of the conventional sucker rod pumping units is always present due to many problems that involve. The study in this case involves both the cinematic and dynamic analysis of the mechanism of the conventional pumping units, making sure that the optimization solution maintain unchanged certain operating parameters of the pumping equipment such as the stroke of the sucker rod column. In the paper is presented a method of determining the optimal dimensions of the structural elements of the mechanism of the conventional pumping units in order to reduce the maximum values of the connection forces in the bearings in the conditions of maintaining unchanged the stroke of the sucker rod column. The simulations have been performed in the case of a C-640D-305-120 pumping unit.
\end{abstract}

Keywords: sucker rod pumping unit, connection forces, optimization

The dimensional optimization of the structural elements that are parts of the conventional pumping units involves the realization of a highly complex study that includes both the kinematical and dynamic analysis of their mechanism [1-3]. For this purpose, an exact determination of the loads to which the component parts are subjected and the dynamic and cinematic modeling of the pumping unit mechanism plays an essential role [4-8]. On the other hand, it is well known that the bearings of the conventional pumping units are some of their most loaded components [5], so for increasing safety in operation a main objective in the optimization study is to reduce the maximum values of the connection forces.

In this paper is presented a method of determining the optimal dimensions of the structural elements of the mechanism of the conventional pumping units in order to reduce the values of the connection forces in the bearings in the conditions of maintaining unchanged the stroke of the sucker rod column. It is also analyzed the influence of the results obtained after the optimization process upon the variation of the motor moment at the crankshaft. Some significant results concerning the cinematic and dynamic analysis of the mechanisms in the perspective of their dimensional optimization that have strongly helped to the achievement of the research from this paper are presented in [9-22]. The optimization method has been transposed by the author into a computer program using Maple programming environment [23]. The experimental records have been processed with the program Total Well Management [24].

\section{Experimental part}

The program Total Well Management [24] has been used for processing the experimental records obtained in the case of a well that is serviced by a C-640D-305-120 pumping unit manufactured by Lufkin (fig. 1).

In establishing the connection forces acting on the bearings was used the record concerning the variation on a cinematic cycle beginning with the cranks angle corresponding to the upward movement of the rod column of the force at the polished rod for the stroke 50 (fig. 2).

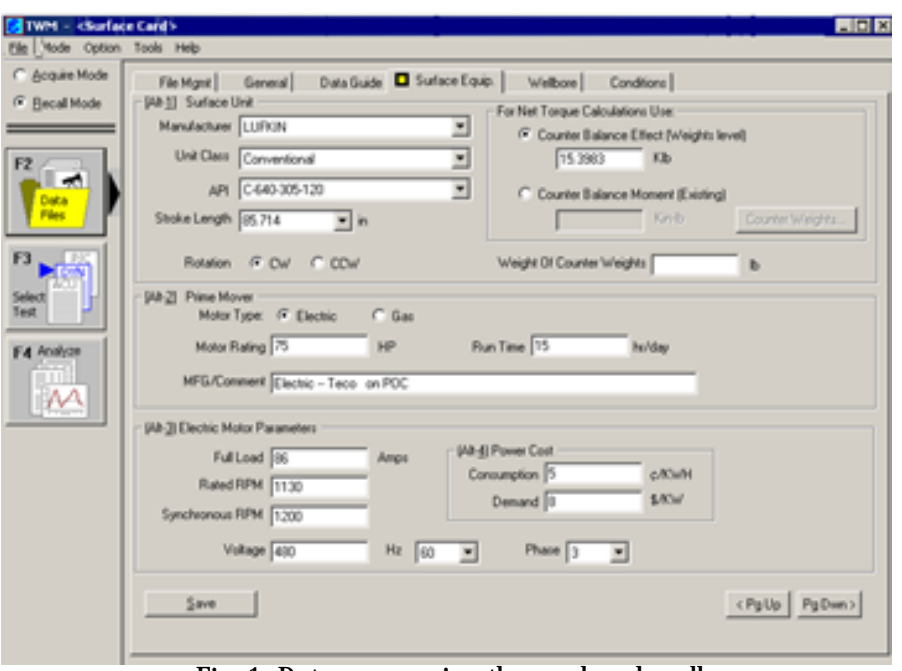

Fig. 1. Data concerning the analyzed well

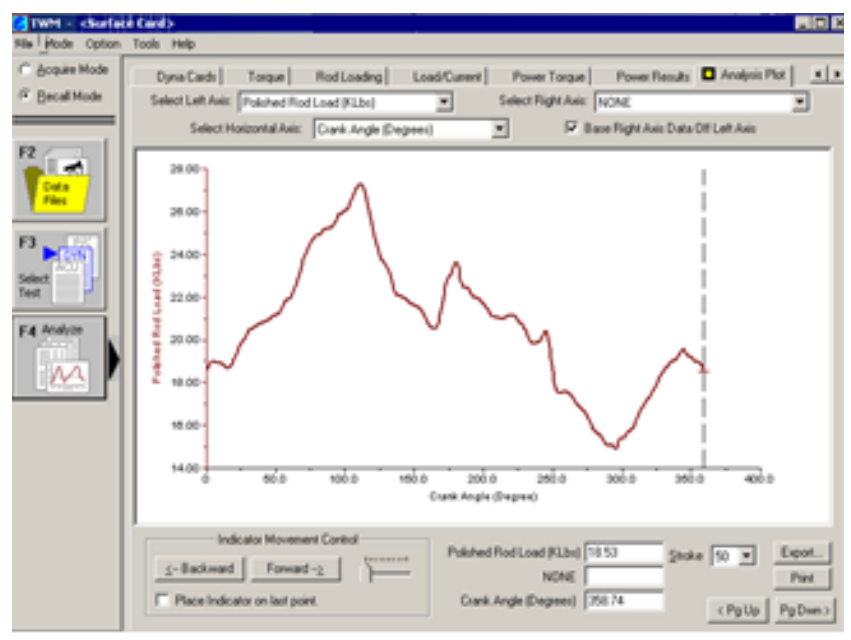

Fig. 2. The variation of the force at the polished rod during the stroke 50

The simulation results obtained for the variation on a cinematic cycle beginning with the cranks angle corresponding to the upward movement of the rod column of the motor moment at the crankshaft have been 
compared with the experimental records established for the stroke 50 (fig. 3).

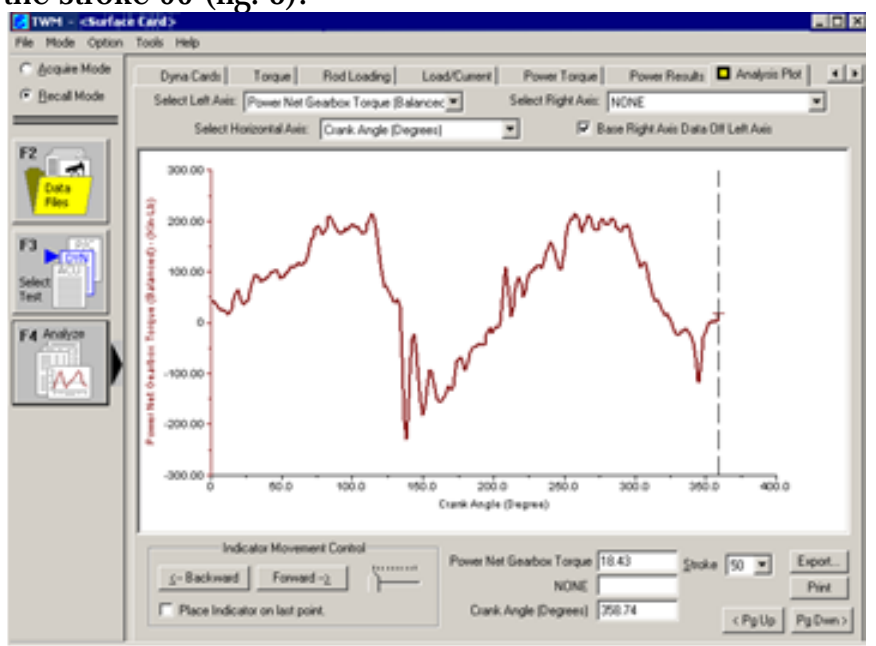

Fig. 3. The variation of the motor moment at the crankshaft during the stroke 50

Dimensional optimization based on the kinetostatic analysis of the mechanism of the conventional sucker rod pumping units

In figure 4 is presented the mechanism of a conventional pumping unit. Were used the following notations: $\mathrm{C}_{1}, \mathrm{C}_{2}$ and $C_{3}$ are the mass centers of the cranks, connecting rods and of the rocker, respectively; $m_{c G}$ is the total mass of the balancing counterweights; $m_{1}$ is the total mass of the connecting bearings between the cranks and the connecting rods; $m_{2}$ is the mass of the spherical connecting bearing between the connecting rods and the rocker; $m_{t r}$ is the mass of the equalizer traverse; $m_{C B}$ is the mass of the rocker head considered to be concentrated in point $D^{\prime} ; M_{m}$ is the motor moment at the crankshaft; $\bar{F}$ is the force acting at the end of the polished rod.
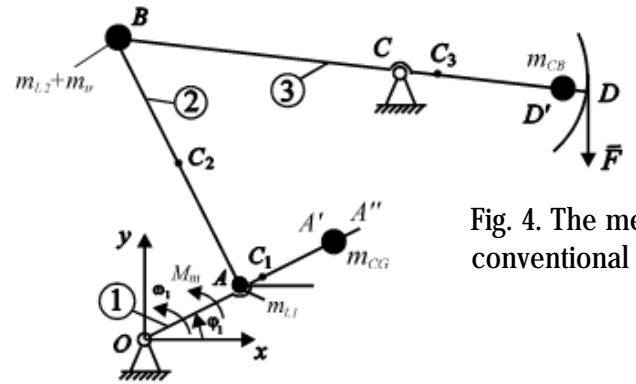

Fig. 4. The mechanism of a conventional pumping unit
In figure 5 are presented the load schemes of the rocker, of the connecting rods and of the cranks [ 5$]. G_{;} ; j=\overline{1.3}$, are the weight forces of the cranks, of the connecting rods and of the rocker, respectively; $\bar{G}_{c G}$ is the weight force of the balancing counterweights; $G_{1}$ is the weight force of the two crank pin bearings (it has been considered that half of the weight of these bearings is concentrated on the connecting rods, the rest remaining concentrated on the cranks); $\bar{G}_{t, 2}$ is the weight force of the equalizer bearing; $\overline{G_{t r}}$ is the weight force of the equalizer; $\bar{G}_{c}$ is the weight force of the horsehead; $\bar{F}_{i j,} j=\overline{1.3}$, are the inertia forces corresponding to the cranks, connecting rods and to the rocker, respectively; $\bar{M}_{i, j}, j=1.3$, are the inertia moments corresponding to the connecting rods and to the rocker; $\bar{F}_{i C G} \bar{F}_{i L L}, \bar{F}_{i t 2}, \bar{F}_{i t,}$ and $\bar{F}_{i C B}$ are the inertia forces corresponding to the balancing counterweights, to the two crank pin bearings, equalizer bearing, equalizer and to the horsehead, respectively.

$\bar{F}_{03 x}$ and $\bar{F}_{33 y}$ representthe projections on $x$ and yaxes of the connection force from the centre bearing. Are also represented the projections on $x$ and $y$ axes of the connection forces: $\bar{F}_{23}$ from the equalizer bearing acting on the rocker; $\bar{F}_{32}$ from the equalizer bearing acting on the equalizer; $\bar{F}_{12}$ from the two crank pin bearings acting on the connecting rods; $\bar{F}_{27}$ from the two crank pin bearings acting on the cranks; $F_{01}$ from the two joints connecting the two cranks and the output shaft of the reducer.

The manner of determining of the connection forces and of the motor moment $M_{m}$ at the crankshaft is presented in [5]. A computer program that allow the determining of the optimal dimensions of the elements of the mechanism of the conventional pumping units in order to reduce the values of the connection forces in the bearings has been developed by the author using the powerful symbolic calculus functions included in Maple programming environment. For optimization calculus has been used the function NLPSolve included in the Optimization package of Maple [23]. In this way can be determined the dimensions of the component elements of the mechanism of the conventional pumping units that lead to minimizing of the maximum value of the connection force from the centre bearing that is the most loaded bearing during operation $\left(F_{03}\left(O A, A B, B C, C D, x_{C}, y_{C}\right)\right)_{\varphi_{i}-\varphi_{i g},}$, where $\mathrm{m}_{\mathrm{c}}$ and $\mathrm{y}_{\mathrm{C}}$ are the coordinates of the point $C$ (fig. 4) and $\varphi_{1 F \max }$ represents the value of the angle $\varphi$, where the maximum of the force at the polished rod is reached.

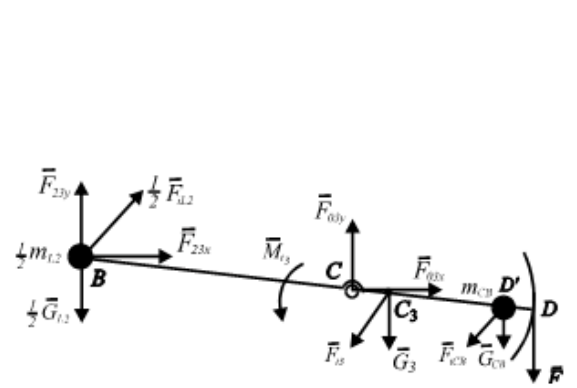

a)

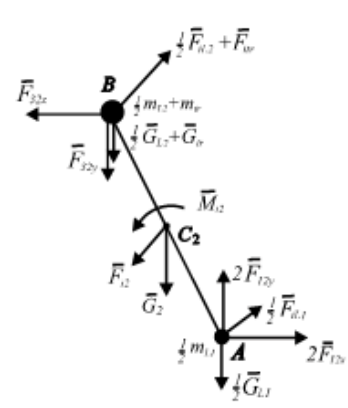

b)
Fig. 5. Load schemes of the rocker (a), of the connecting rods (b) and of the cranks (c)

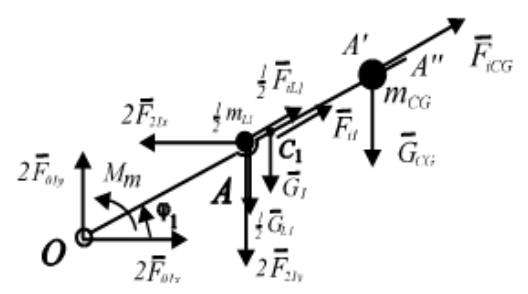

c) 


\section{Results and discussions}

The simulations have been performed in the case of a C-640D-305-120 pumping unit produced by Lufkin [25], whose component elements have the following dimensions: $O A=30 \mathrm{in}$. $(0.762 \mathrm{~m}) ; A B=133.5 \mathrm{in}$. (3.3909 $\mathrm{m}) ; B C=111.09$ in. $(2.8217 \mathrm{~m}) ; C D=155$ in. $(3.937 \mathrm{~m})$; and the coordinates of the point $C$ (fig. 4) are: $x_{c}=111$ in. $(2.8194 \mathrm{~m})$ and $\mathrm{y}_{\mathrm{f}}=138 \mathrm{in}$. (3.5052 $\left.\mathrm{m}\right)$. The values of the crank angle $\varphi_{1}$ (fig. 4) corresponding to the beginning of the upward and downward movements of the sucker rod column are: $\varphi_{1 d}=88.976^{\circ}$ and $\varphi_{1 a}=266.929^{\circ}$, respectively [5].

The simulations have been accomplished by considering the following values of the other parameters involved in calculations: $C D^{\prime}=140$ in. $(3.556 \mathrm{~m}) ; O A^{\prime}=54.5 \mathrm{in}$. $(1.3843 \mathrm{~m}) ; m_{11}=88 \mathrm{~kg} ; m_{12}=169 \mathrm{~kg} ; m_{t \pi}=580 \mathrm{~kg} ; m_{C B}$ $=840 \mathrm{~kg} ; q_{1}=722 \mathrm{~kg} / \mathrm{m} ; q_{2}=34 \mathrm{~kg} / \mathrm{m} ; q_{3}=300 \mathrm{~kg} / \mathrm{m}$ $\left(q_{1}, q_{2}\right.$ and $q_{3}$ are the linear masses of the cranks, connecting rods and of the rocker, respectively). The work angular speed of the cranks has been of $6.667 \mathrm{rot} / \mathrm{min}$.

The variation on a cinematic cycle of the force $F$ at the end of the polished rod (fig. 2) has been expressed according to the angle $\varphi$, with a polynomial function whose coefficients have been calculated with the method of the least squares [26]:

$$
F\left(\varphi_{1}\right)=c_{0}+c_{1} \cdot \varphi_{1}+c_{2} \cdot \varphi_{1}^{2}+\ldots+c_{m} \cdot \varphi_{1}^{m}
$$

In figure 6 are presented the values of the coefficients $c_{i}, i=0, m$, in the order in which they are found in the polynomial function (it has been consider $m=25$ ).
The variation of the force at the polished rod during a cinematic cycle beginning with the angle $\varphi_{1 d}$ obtained using the polynomial function is represented by the curve 1 in figure 7 and the curve 2 corresponds to the variation of its measured values.

In figure 8 the curve 1 represents the variation on a cinematic cycle of the motor moment at the crankshaft beginning with the angle $\varphi_{1 \text { obtained after simulations }}$ and the curve 2 corresponds to the variation of its measured values for the stroke 50 .

Figure 8 highlights a good accordance between the values of the motor moment at the crankshaft obtained with the simulation program and its measured values.

After performing the optimization calculation that aimed the minimization of the maximum value of the connection force $\left(F_{03}\left(O A, A B, B C, C D, x_{C}, y_{C}\right)\right)_{\varphi_{1}-\varphi_{i}, F=}$, where in this case $\varphi_{1 \text { max }}=3.44$ (fig. 7), have been obtained the following values for the dimensions of the component elements of the pumping unit mechanism: $O A=0.737 \mathrm{~m} ; A B=3.604$ $\mathrm{m} ; B C=2.492 \mathrm{~m} ; C D=3.489 \mathrm{~m} ; \mathrm{x}_{c}=2.396 ; \mathrm{y}_{c}=2.979 \mathrm{~m}$. In applying the function NLPSolve included in the Optimization package of Maple has been considered that the values for $O A, A B, B C, C D, x_{c}$ and $y_{c}$ can vary with \pm $15 \%$ of their initial values. Also, it has been imposed the condition of maintaining unchanged the stroke of the sucker rod column.

In figures $9 \div 13$ are presented the variation on a cinematic cycle beginning with the angle $\varphi_{1 d}$ of the values of the connection forces $\mathrm{F}_{01^{\prime}} \mathrm{F}_{12^{\prime}} \mathrm{F}_{23^{\prime}} \mathrm{F}_{03^{\prime}}$ and of the motor

\footnotetext{
$[17.417407511304906014002831074563518,86.803565974775130602802445560336066,-4764.068570356465909030223393742348,18201.586555951601925277642824:$ $-113552.0128728603276482707773132363,459060.8350028338277138946985375986,0.0 .1278326709200622210832945436283242 \quad 10^{7}, 0.2562182404735690254683:$ . $-0.382752850833889559064410871566976210^{7}, 0.437953600293319741890528179674404610^{7}, 0.392031646011182851583872675718941210^{7}$.

$0.2790055331379597599051219073296706 \quad 10^{7},-0.1597890433814868062325367050567758 \quad 10^{7}, 7428129313409497676408137066269117,-281880.0392852341094$ .87569.98930237686579669163495045615.22275.40624664474279021544457175185, .4627 .002003361025878775705445327345 . .780 .139617566978675241204898 $105.69743138003360288436056452126355,-11.329395734337928730990473834046929,0.9382517928910297828223841978620232,0.057867165008296694917040$ $0.002500963062098182854500713741393420,-0.00006755200368002639530235248542581004,0.857841189774684479341488400144103010^{-6} \mathrm{~J}$
}

Fig. 6 . The values of the coefficients of the polynomial function corresponding to the force at the polished rod

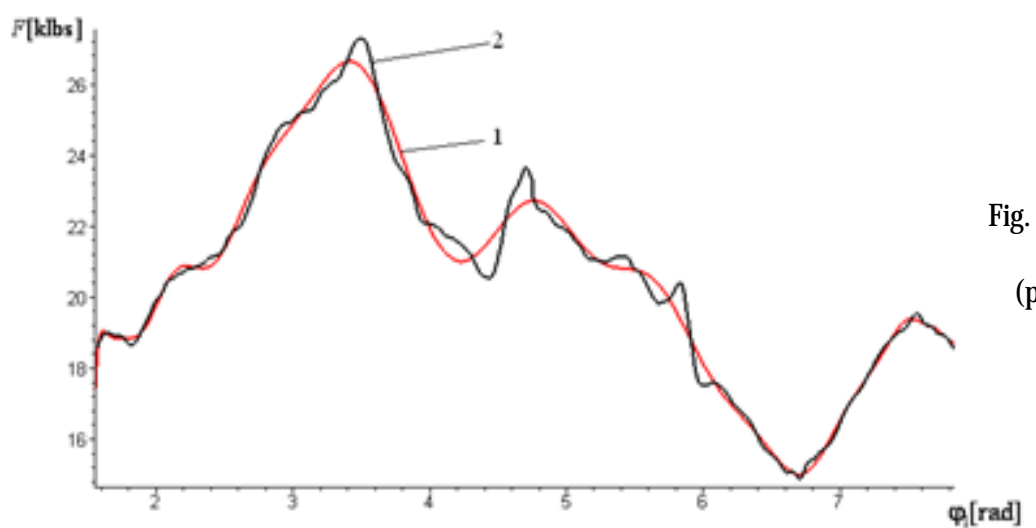

Fig. 7. The variation of the force at the polished rod during the stroke 50

(polynomial function - curve 1; experimental - curve 2)

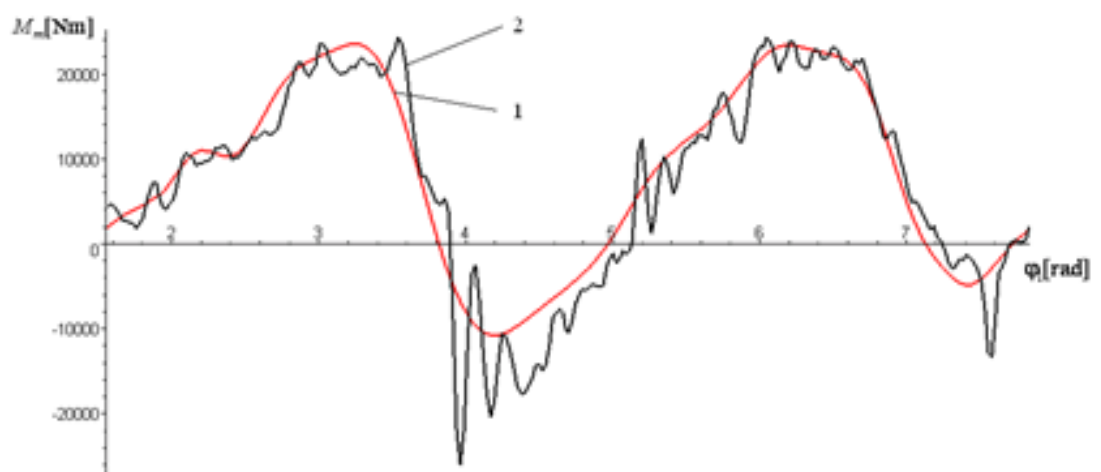

Fig. 8. The variation of the motor moment at the crankshaft during the stroke 50

(simulation - curve 1; experimental - curve 2) 
moment $M_{m}$ at the crankshaft. The curves 1 correspond to the simulation results obtained after performing the optimization calculation and the curves 2 correspond to the values of the connection forces and of the motor moment at the crankshaft obtained with the initial values of the dimensions of the component elements of the pumping unit mechanism.
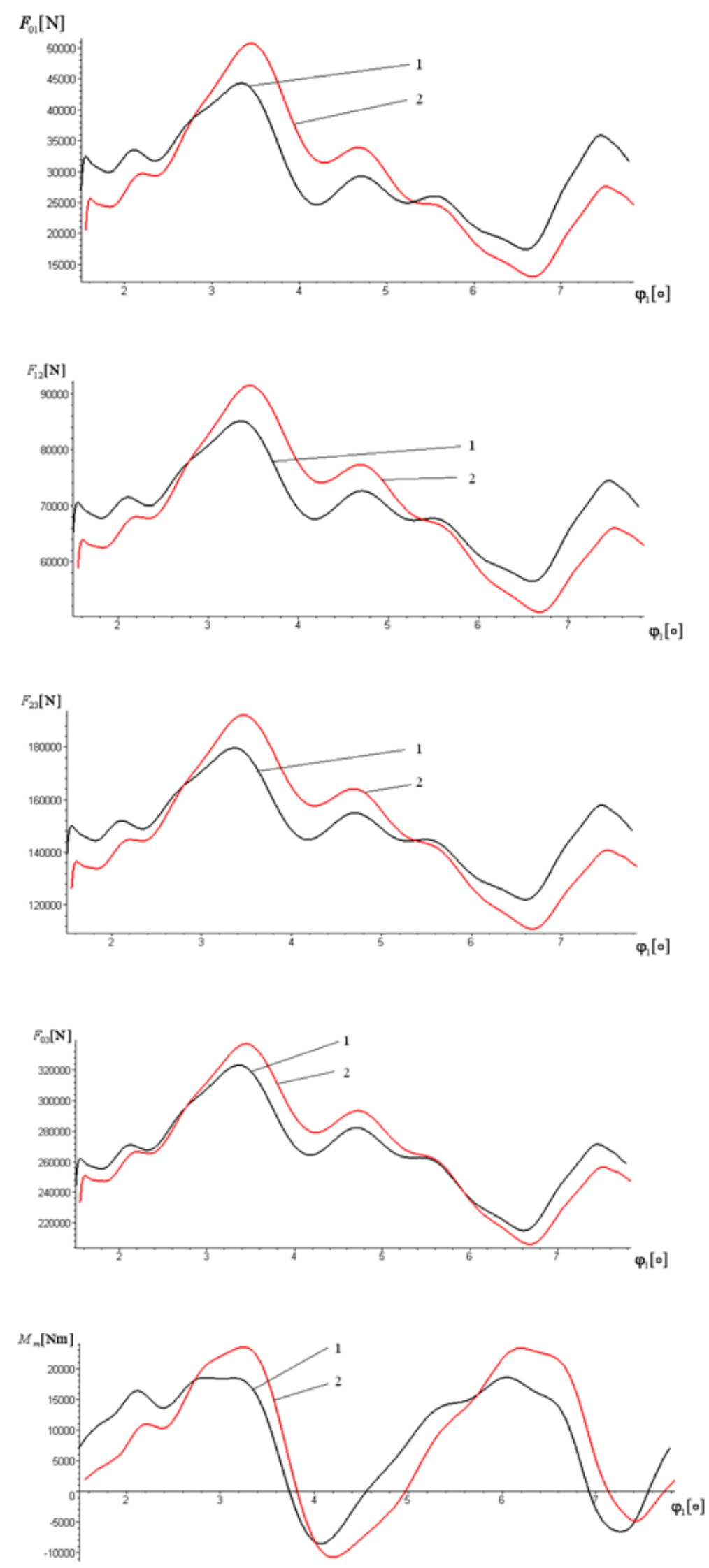

Fig. 9. The variation on a cinematic cycle of the connection force $F_{01}$ (after optimization - curve 1; before optimization - curve 2)

Fig. 10. The variation on a cinematic cycle of the connection force $\mathrm{F}_{12}$ (after optimization - curve 1; before optimization - curve 2)

Fig. 11. The variation on a cinematic cycle of the connection force $\mathrm{F}_{23}$ (after optimization - curve 1 ; before optimization - curve 2)

Fig. 12. The variation on a cinematic cycle of the connection force $\mathrm{F}_{03}$ (after optimization curve 1; before optimization - curve 2)

Fig. 13. The variation on a cinematic cycle of the motor moment $\mathrm{M}_{m}$ (after optimization - curve 1; before optimization - curve 2) 


\section{Conclusions}

In this paper has been presented a method of determining the optimal dimensions of the structural elements of the mechanism of the conventional pumping units in order to reduce the maximum values of the connection forces in the bearings in the conditions of maintaining unchanged the stroke of the sucker rod column. The optimization method has been transposed by the author into a computer program using Maple programming environment. For optimization calculus has been used the Optimization package of Maple. It was also analyzed the influence of the results obtained after the optimization process upon the variation of the motor moment at the crankshaft. The simulations performed in the case of a C-640D-305-120 pumping unit highlighted the extremely high values of the connection forces acting in the bearings of the analyzed pumping unit and the fact that by optimization their maximum values have decreased. Also, the simulation results highlighted a significant decrease of the maximum values of motor moment at the crankshaft after optimization.

\section{References}

1.GIBBS, S G., Predicting the behavior of sucker-rod pumping systems, Journal of Petroleum Technology, 1963 (July), p. 769-778

2.GIBBS, S G., Computing gearbox torque and motor loading for beam pumping units with consideration of inertia effects, Journal of Petroleum Technology, 1975 (September), p. 1153-1159

3.POPOVICI, A., Equipment for the exploitation of oil wells (in Romanian), Technical Publishing House, Bucharest, 1989

4.BADOIU, D., TOMA, G., Research concerning the identification of some parameters of a sucker rod pumping unit, Rev. Chim. (Bucharest), 68, no. 10, 2017, p. 2289-2292

5.BADOIU, D., TOMA, G., Research concerning the kinetostatic analysis of the mechanism of the conventional sucker rod pumping units, Rev. Chim. (Bucharest), 69, no. 7, 2018, p. 1855

6.BADOIU, D., TOMA, G., Research concerning the correlations between some experimental results in the case of a sucker rod pumping installation, Rev. Chim. (Bucharest), 69, no.11, 2018, p. 3060 7.BADOIU, D., TOMA, G., Research concerning the predictive evaluation of the motor moment at the crankshaft of the conventional sucker rod pumping units, Rev. Chim. (Bucharest), 70, no. 2, 2019, p. 378

8.TOMA, G., BADOIU, D., Research concerning the influence of some constructive errors on the dynamics of a pumping unit, PetroleumGas University of Ploiesti Bulletin, Technical Series, Vol. 63, no. 4, 2011, p. 27-30

9.BADOIU, D., TOMA, G., On a dynamic optimisation problem of the quadrilateral mechanism, Journal of the Balkan Tribological Association, Vol. 22, no. 1, 2016, p. 250-260

10.BADOIU, D., On the dynamic behavior of a quadrilateral mechanism, Petroleum-Gas University of Ploiesti Bulletin, Technical Series, Vol. 64, no. 2, 2012
11.VASILESCU, S., BADOIU, D., On the dynamic analysis of a family of quadrilateral mechanisms, Petroleum-Gas University of Ploiesti Bulletin, Technical Series, Vol. 63, no. 2, 2011, p. 7-10

12.BADOIU, D., On the movement equation of the quadrilateral mechanism, Petroleum-Gas University of Ploiesti Bulletin, Technical Series, Vol. 67, no. 2, 2015, p. 67-72

13.BADOIU, D., On the calculus of the equilibrium moment in the case of a plane mechanism, Petroleum-Gas University of Ploiesti Bulletin, Technical Series, Vol. 62, no. 4B, 2010, p. 23-28

14.BADOIU, D., On the calculus of the necessary motor moment for the running of the plane mechanisms, Petroleum-Gas University of Ploiesti Bulletin, Technical Series, Vol. 61, no. 4, 2009, p. 79-82

15.BADOIU, D., Research concerning the dynamic analysis of plane mechanisms structures, Petroleum-Gas University of Ploiesti Bulletin, Technical Series, Vol. 61, no. 2, 2009, p. 29-32

16.BADOIU, D., On the establishing and solving of the movement equation in the case of the plane mechanisms, Petroleum-Gas University of Ploiesti Bulletin, Technical Series, Vol. 67, no. 3, 2015, p. 87-93

17.TOMA, G., BADOIU, D., On the cinematic analysis of a mechanism of fourth class, Petroleum-Gas University of Ploiesti Bulletin, Technical Series, Vol. 64, no. 1, 2012, p. 69-72

18.TOMA, G., BADOIU, D., Research Concerning the Calculus of the Equilibrium Moment in the Case of a Plane Mechanism Using the Dynamic Model, Petroleum-Gas University of Ploiesti Bulletin, Technical Series, Vol. 67, no. 2, 2015, p. 93-98

19.BADOIU, D., On the calculus of the equilibrium moment for a mechanism with three independent contours, Petroleum-Gas University of Ploiesti Bulletin, Technical Series, Vol. 67, no. 1, 2015, p. 99-104

20.BADOIU, D., On the positional and cinematic analysis of a mechanism with three independent contours, Petroleum-Gas University of Ploiesti Bulletin, Technical Series, Vol. 66, no. 2, 2014, p. 55-58

21.SHABANA, A.A., Dynamics of multibody systems, Cambridge University Press, 2005

22.SHIGLEY, J.E., UICKER JR., J.J., Theory of machines and mechanisms, McGraw-Hill, 1981

23.MONAGAN, M.B., GEDDES, K.O., HEAL, K.M., LABAHN, G., VORKOETTER, S.M., MCCARRON, J ., DEMARCO, P., Maple Introductory Programming Guide, Maplesoft, a division of Waterloo Maple Inc., 2005

24.***, Total Well Management Help Manual, Echometer Company, Texas

25.***, Conventional Crank Balanced Pumping Units, Lufkin Oilfield Products Group, Houston, Texas

26.DODESCU, G., TOMA, M., Numerical calculus methods (in Romanian), Didactical and Pedagogical Publishing House, Bucharest, 1976

Manuscript received: 19.06 .2018 